\title{
HOW COMMON IS HIRSCHSPRUNG'S DISEASE AT THE TERTIARY CARE CENTER IN WESTERN TAMILNADU: A CROSS SECTIONAL STUDY
}

\author{
S. Shifa ${ }^{1}$, K. Kamaleshwari ${ }^{2}$ \\ ${ }^{1}$ Assistant Professor, Department of Pathology, Madurai Medical College. \\ ${ }^{2}$ Assistant Professor, Department of Pathology, Madurai Medical College.
}

\begin{abstract}
BACKGROUND: A rare disease of the newborn, Hirschsprung's disease has evolved since Harold Hirschsprung's days. In all the studies that were documented, the incidence was given as one in 5000 live births. There in not much study about it in western Tamilnadu. So, we thought we would study the incidence, age at which it is diagnosed and the sex prevalence of this rare disease in our setup.
\end{abstract}

STUDY DESIGN: Descriptive cross sectional study

AIM: To analyze incidence, age and sex ratio of the children with Hirschsprung's disease in our setup.

METHOD: This study was carried over a period of two years [November 2011- November 2013]. Biopsies that were sent as suspected Hirschprung's disease during the study period was analysed. The diagnosis was done using haematoxylin eosin staining and acetylcholine esterase staining of the frozen sections.

RESULTS: Incidence of Hirshprung's disease was calculated based on positive acetylcholine esterase stain and haematoxylin stain. The incidence calculated was 1.54/5000 live births. Mean age at which the disease was diagnosed was 1.03 in our setup and there was a male predominance.

CONCLUSION: Incidence, age and sex prevalence of our study group correlated with other studies.

KEYWORDS: Staining, Age, Male.

HOW TO CITE THIS ARTICLE: S. Shifa, K. Kamaleshwari. "How Common is Hirschsprung's Disease at the Tertiary Care Center in Western Tamilnadu: A Cross Sectional Study". Journal of Evolution of Medical and Dental Sciences 2015; Vol. 4, Issue 92,

November 16; Page: 15782-15785, DOI: 10.14260/jemds/2015/2281.

INTRODUCTION: Hirschsprung's disease is a rare disease of the newborn. The basic defect is the failure of ganglion cells to migrate and populate the intestinal musculature. It was first described by a Danish physician Harold Hirschprung and hence was named after him. The basic understanding of this disease has evolved much since then. He thought that the pathology existed in the dilated segment.[1] Later, constricted portion was identified as the diseased part and the genetic studies added on to our understanding of this disease. Diagnostic part too had evolved. Manometry, barium studies, histopathological examination of the full thickness biopsies to examining suction biopsies, frozen section staining, immunohistochemistry and finally genetic studies and syndromic approach are the evolved diagnostic approaches.

Surgeons part also had evolved from the days of Swenson's to Duhamels modification with a later addition of laproscopic assisted surgeries. The incidence of this disease, according to international standards is one in 5000 live births. Not much work was done to calculate the incidence in Tamilandu, India. With this background we wanted to study the incidence of this disease, age at which the disease is diagnosed and the sex prevalence in our setup.

Financial or Other, Competing Interest: None.

Submission 23-10-2015, Peer Review 24-10-2015,

Acceptance 05-11-2015, Published 16-11-2015.

Corresponding Author:

Dr. S. Shifa,

\#82, J. N. Nagar,

Old Natham Road,

Madurai-625017.

E-mail: shifafrin@gmail.com

DOI:10.14260/jemds/2015/2281
MATERIALS AND METHODS: Biopsies taken from the rectal mucosa two centimeters from the anal verge and sent in saline were included in our study. Biopsies that were fixed in formalin and that contain squamous epithelium were excluded from our study. Preliminary investigations like radiography were done by the pediatric surgeons and then rectal mucosal biopsies were sent in saline. Along with the rectal biopsy specimens, biopsies from various levels of intestine were also sent to assess the extent of the disease.

A requisition accompanied the specimen with a mention on the history and site from where the biopsies were taken. The specimens were divided equally for formalin fixation and cryostat sectioning. Formalin fixed specimens were processed and stained with eosin and haematoxylin and frozen sections of $10 \mu \mathrm{m}$ thickness were taken and stained with acetylcholine esterase and rapid eosin and haematoxylin.

The absence of ganglion cells and the presence of hypertrophic nerves in the eosin and haematoxylin sections and greenish black nerve fibers with absence of ganglion cells in the acetylcholine esterase stained sections were the diagnostic criteria used to identify Hirschprungs disease. The incidence of HSD, age wise break up and sex incidence was calculated.

RESULTS: Incidence,age and sex ratio of the children with Hirschprung's disease in our setup was calculated from the twenty cases that were referred. The live birth rate in our district was 51,818 per year. Sixteen cases were positive for Hirschsprung's disease in our hospital. Because our hospital is a tertiary referral center for this district, the incidence of live birth of this district was taken into account when the incidence ratio of Hirschsprung's disease was calculated. 
Number of New Cases/Person-Time at Risk [that is the all live born infants] was the formula used to calculate the incidence. The incidence in our study group was 1.54 per 5000 live births. This incidence correlated with the study by Parisi \&Kapur.[2] [1 in 5000 newborns].

The mean age of children in whom biopsy was done was 1.6 years. Ten [62.5\%] out of sixteen cases were diagnosed within a year of their birth in our study, [Table2]. In our study, the age incidence falls within the range of 0.35494 and 1.69906 years. When the age at which the disease occurred was statically analyzed, mean age of occurrence was 1.03 years. The 95\% Confidence interval was 0.35494 and 1.69906 years. This falls within the standard deviation which was 1.30712. Fleurdelorijn, Johannes b. Reitsma, Wieger P.

Voskuij et al had quoted that the mean age of occurrence in their study as 5.3months. ${ }^{[3]}$ Robertas Bagdzevičius et al in their study had noted the mean age of occurrence was 3 months to 6.5 years, which is in coherence with our study.[4]

When compared with those patients referred at the age less than one year and to those referred at ages more than one year the following results were observed. When clinical diagnosis, was made in children less than one year, ten out of eleven turned out to be having Hirschsprung's disease [Table 3].

But in the age group more than one year, out of nine cases suspected clinically of Hirschsprung's disease only six turned out to be positive for Hirschsprung's disease. The correlation between the clinical diagnosis and cases diagnosed using acetylcholine esterase was $90 \%$ if the rectal biopsies were sent before one year of age. But when the biopsies were sent after one year of age, the correlation between the clinical diagnosis and cases diagnosed by acetylcholine esterase was $60 \%$.

Robertas Bagdzevičius et al, in his study had observed $76 \%$ and $11-18 \%$ in ages less than and more than one year respectively. ${ }^{[4]}$ Ghosh and Griffiths had stated in their study a child with late onset of constipation is less likely to have Hirschsprung's disease.[5] Out of the twenty cases that were referred, 16 cases were diagnosed as Hirschsprung's disease. Male predominance was noted in our study, 15 were male, [93.75\%] and one was a female child[6.25\%], [Table 4]. This observation correlates with almost all the studies in Hirschsprung's disease in which male cases predominate (Ratio is $4: 1$ to 6:1).[6] The 95\% confidence interval based on the sex ratio extends from 12.22 to 30.89 .

As indicated in Table5, Hirschsprung's disease involving recto-sigmoid part of the colon was more prevalent (15 out of 16 cases) in the population studied. Bax, Knob served in his study that in $80 \%$ of the cases, aganglionosis involved the recto-sigmoid colon. [7] One case had total bowel aganglionosis and she was a female. In a study by Kleihaus et al, the male predominance was observed less in the case of total aganglionosis which correlated with this study.[8]

DISCUSSION: Hirschsprung's disease [HSD] is a rare genetic disorder. It is classified under the category neurocristopathies - conditions originating from abnormal development of neural crest cells. Absence of intramural parasympathetic ganglion cells in the large intestine is the hallmark of this disease.

The enteric nervous system (ENS) is composed of intrinsic neurons and extrinsic nerve fibers. Intrinsic neurons, the cell bodies and processes are located inside the bowel wall and extrinsic nerve fibers project into the gut from autonomic and sensory ganglia according to Furness JB.[9] Although extrinsic innervation modulates the activity of intrinsic neurons, the intrinsic neurons are necessary for the complex reflex pathways that ensure peristaltic activity.

Nerves in both myenteric and submucosal nerve plexuses are a mixture of intrinsic and extrinsic fibers and specialized enteric glial cells. They project into muscularis propria, muscularis mucosa, and lamina propria according to Raj P. Kapur.[10] Neural crest cells are pluripotent cells. They migrate cranio- caudally in the developing embryo generating the neuronal elements and glial elements of the gastrointestinal (GI) tract. This ganglion cell network regulates various functions in the mature intestine.

Arrest in this migration is the pathogenesis of Hirschprungs disease. Several genes, including RET gene, Endothelin-3 and Endothelin type B receptor, transcription factors such as SOX10, PHOX2B or ZFHX1B are implicated in its pathogenesis.[11-15] Both familial and sporadic forms of Hirscchsprungs disease are reported. It is associated with cardiovascular malformations and various syndromes, including Down syndrome, neurofibromatosis, LaurenceMoon or Bardet-Biedl syndrome, multiple endocrine neoplasia, Waardenburg's syndrome, neuroblastoma and Ondine's curse (Haddad syndrome) to name a few.

The commonest presenting symptom in the neonates includes obstruction of the intestine and constipation in case of both infants and adults. Other anamnesis includes abdominal distension, vomiting, and delay of passing meconium stool. Enterocolitis complicates Hirschsprung's disease in Downs's children. "Hirschsprung's disease is characterized by aganglionosis in both the Meissner and myenteric plexus. Acetylcholine esterase staining activity is increased in the coarse parasympathetic neurofibrils present in the lamina propria and in the mucosae" according to MeierRuge, who did extensive research in congenital neuronal malformations.[16]

Diagnosis of Hirschsprung's disease is based on this principle. Three zones are identified in the colon affected by Hirschprungs disease, the narrow segment, transition zone and a dilated proximal bowel segment. Histologically, in the narrowed segment there is aganglionosis and hypertrophic nerve bundles. In the transitional zone, both the hypertrophic nerves and ganglion cells are seen. Dilated colon usually has ganglion cells and no hypertrophic nerve fibers.

The internal sphincter has a natural scarcity of ganglion cell close to the anus for a length about $10 \mathrm{~mm}$ above the dentate line. This is the reason for the general rule to perform biopsies $2-3 \mathrm{~cm}$ proximal to the dentate line, according to Teitelbaum et al.[16] Depending upon the length of the intestine involved, it is grouped as ultra- short segment,short segment, long segment and total aganglionosis. Total aganglionosis particularly involve the female child, even though Hrischprungs disease is more common in male.

Total colonic aganglionosis presents outside the neonatal period, even in the adolescent age group and early adulthood. Pathophysiological process involved in total aganglionosis is different from other forms of HSDs and some of which continue to be active after birth. 
There are two sub-divisions in total aganglionosis based on the length of bowel segments involved:

- Total colonic aganglionosis or TCA -Aganglionotic segment extends from the anal canal to at least the ileocaecal valve, doesn't extend proximal bowel beyond $50 \mathrm{~cm}$ of the ileocaecal valve.

- Small bowel aganglionosis - Aganglionotic segment extend upto small bowel segments. In total aganglionosis there is hypoplasia of the parasympathetic nerves, and hence acetylcholine esterase activity is less accentuated.(17) Solari et al in his report had remarked about the lack of myenteric interstitial cell of Cajal in the smooth muscle layer and a reduced hypertrophied nerve trunk in total colonic aganglionosis.(18) Hence,this condition is very difficult to diagnose.

Diagnostics include radiography, manometry, rectal biopsies and noninvasive methods like erythrocyte acetylcholine esterase. Rectal biopsies are the gold standard in the diagnosis of Hirschsprungs disease. Stains used in the rectal biopsies include Haematoxylin and Eosin, Acetylcholine esterase on the frozen sections, Nicotinamide adenine dinucleotide phosphate diaphorase (NADPH-d), Nitric oxide synthase (NOS), Peripherin and c-kit, Calretinin, antibodies to neurofilament 68 and tubulin, protein gene product 9.5 (PGP9.5), antigen CD56 (CD56), Cathepsin D, RET, BMPR1A, and bcl-2 immunohistochemistry can be used.

$\mathrm{Bcl} 2$ in particular are expressed in the immature small ganglion cells,hence useful in very small infants. Differential diagnosis of HSD depends on the site. For the Lesions in the large intestine,hypoplastic left colon syndrome,ano-rectal malformation,intestinal neuronal dysplasia and Meconium plug syndrome are the differentials. In the case of small intestine, malrotation, volvulus, intestinal atresia and cystic fibrosis are the differentials. Other causes like scleroderma, amyloidosis, myotonic and other dystrophies,mitochondrial myopathy, narcotics, electrolyte abnormalities, hypothyroidism,sepsis and very low birth weight infant are also included in the differentials.

The incidence ranges from one in 4400 to one in 7000 live births, according to Teitelbaum et al.[16] Most studies quote the incidence as one in 5000 live births.[19-22] In our study the incidence was 1.54 per 5000 live births, which correlated with other studies. The incidence of Hisrchsprungs disease is higher among Asians when compared with the rest.

Male predominance is noted in the study of Isfaq et al and Suita's study.[1,23] Male to female ratio in Isfaq's study was 5:1 and in Suita's study it was 3:1 and in Lee's study it was $4: 1 .[1,24]$ In Mabula et al's study male to female ratio was 3.6:1.[25] The global sex ratio ranges from 2.9: 1 to 4.5: 1.[26-28] In our study male to female ratio was $15: 1$. The reason for this male predominance is unknown.

In Mabula et al's study, only $5.5 \%$ of patients were diagnosed during the neonatal period and most of the patients presented after the first year of life. In developed countries more than $90 \%$ of the cases were diagnosed during the neonatal period.[29] In our study only $25 \%$ of the cases, that is four out of sixteen cases were diagnosed during the neonatal period. The mean age at which the disease occurred was calculated in our setup and it was 1.03 years. Thus, all the indices we studied correlated with global indices.

CONCLUSION: The incidence was 1.54 per 5000 live births. There was a male predominance with male to female ratio of 15:1. Mean age of occurrence was 1.03 years. When rectal biopsy specimen of age less than one year was assessed, the clinical diagnosis correlated $90 \%$ with that of histopathological diagnosis, whereas when rectal biopsy specimen was analysed from the patients refereed at the ages more than one year, the clinical diagnosis correlated $60 \%$ with that of histopathological diagnosis. The incidence, age and the sex ratio of our study was in correlation with other studies.

\section{REFERENCES :}

1. Ishfaq M Ahmad UF, Manzoor S. Hirschsprung's disease; diagnosis and management: experience at Ibn-e-Siena and Nishtar Hospital, Multan. Professional Med J 2014; 21(1): 020-026.

2. Kapur RP. Neuropathology of paediatric chronic intestinal pseudo-obstruction and related animal models. J Pathol. 2001; 194:277-88.

3. Fleur de Lorijn, Johannes B. Reitsma, Wieger P. Voskuijl, Daniel C. Aronson, Fiebo J. ten Kate, Anne M.J.B. Smets, Jan A.J.M. Taminiau, Marc A. Benninga. Diagnosis of Hirschsprung's Disease: A Prospective, Comparative Accuracy Study of Common Tests. The Journal of Pediatrics, June 2005, 146(6):787-792.

4. RobertasBagdzevičius, Vytaut as Vaičekauskas, SigitaBagdzevičiūtè et al, Experience of acetylcholinesterase histochemistry application in the diagnosis of chronic constipation in children, Medicina (Kaunas) 2007; 43- 45.

5. Ghosh A, Griffiths DM. Rectal biopsy in the investigation of constipation. Arch Dis Child 1998; 79:266-8.

6. Edery P, Lyonnet S, Mulligan LM, etal. Mutations of the RET proto-oncogene in Hirschsprung's disease. Nature1994; 367:378-80.

7. Bax, KN. Duhamel lecture: the incurability of Hirschsprung's disease. Eur J Pediatr Surg. 2006 Dec; 16(6):380-4.

8. Kleinhaus S, Boley SJ, Sheran M, Seiber WK Hirschprung's disease: a survey of the surgical section of American academy of Paediatrics. J Paedtr.Surg. 1979:14:588-597.

9. Furness JB. In: The Enteric Nervous System.Boston, MA:Blackwell Publishing, 2006:274.

10. Raj P. Kapur, MD, PhD, Can We Stop Looking? Immunohistochemistry and the Diagnosis of Hirschsprung Disease, Am J Clin Pathol 2006;126:9-12.

11. Kruger GM, Mosher JT, Tsai YH, Yeager KJ, Iwashita T, Gariepy CE, Morrison SJ Temporally distinct requirements for endothelin receptor $B$ in the generation and migration of gut neural crest stem cells. Neuron 2003:40:917-929.

12. Gariepy CE Intestinal motility disorders and development of the enteric nervous system. Pediatr Res 2001:49:605613. 
13. Natarajan D, Marcos-Gutierrez C, Pachnis V, de Graaff E Requirement of signalling by receptor tyrosine kinase RET for the directed migration of enteric nervous system progenitor cells during mammalian embryogenesis. Development 2002:129:5151-5160.

14. Iwashita T, Kruger GM, Pardal R, Kiel MJ, Morrison SJ Hirschsprung disease is linked to defects in neural crest stem cell function. Science 2003:301:972-976.

15. R Gath, A Goessling, et al, Analysis of the RET, GDNF, EDN3, and EDNRB genes in patients with intestinal neuronal dysplasia and Hirschsprung disease, Gut: 2001, 48:671675.

16. Meier-Ruge W, Lutterback P, Herzog B, et al. Acetylcholinestase activity in suction biopsies of the rectum in the diagnosis of Hirschsprung's disease. J Pediatr Surg1972; 7(1):11

17. Teitelbaum DH, Coran AG, Weitzman JJ, et al. Hirschsprung's Disease and Related Neuromuscular Disorders of the Intestine. In: O'neill JA, Rowe MI, Grosfeld JL, editors. 5th edition. Mosby.

Year Book, Inc. 1998;.1381- 424

18. Solari V, Piotrowska AP, Puri P. Histopathological differences between recto-sigmoid Hirschsprung's disease and total colonic aganglionosis.

PediatrSurgInt 2003;19:349-54

19. Godbole Koumudi ,The Many Faces of Hirschsprung's Disease, Indian Pediatrics,2014,41:1115-1123.

20. Langer JC: In Principle and Practice of Pediatric Surgery. 4th edition. Edited by Colombani PM, Foglio RP, Skinner MA Oldham KT. Philadelphia: Lippincott, Williams and Wilkins; 2005:2. 1348-63.

21. Teltelbaum DH, Coran AG: In Hirschsprung's Disease and Related Neuromuscular Disorders of the Intestine. 6th edition. Edited by O'Neill JA Jr, Fonkasrud EW, Coran AG Grosfeld JL. Philadelphia: Mosby-Elservier; 2006:2.151459.

22. Meza-Valencia BE, de Lorimier AJ, Person DA: Hirschsprung's disease in the U.S. associated Pacific Islands: more common than expected.

Hawaii Med J 2005, 64:96-98.

23. Suita S, Taguchi T, Leiri S, Nakatan Suji T. Hirschsprung's disease in Japan: Analysis of 3852 patients based on nationwide survey 30 years. Journal of Paediatric Surgery 2005; 40:197- 201.

24. Lee SL, Dubois JJ. Hirschsprung Disease, available at: http:// www.emedicine.com/med/topic1016.htm. Last Updated: August 5, 2005.

25. Mabula J, Kayange N, Manyama M, Chandika A, Rambau P and Chalya P, Hirschsprung's disease in children: a five year experience at a University teaching hospital in northwestern Tanzania. BMC Research Notes 2014 7:410.
26. Ameh EA, Chirdan LB: Neonatal Intestinal Obstruction in Zaria, Nigeria.East Afr Med J 2000, 77:510-513.

27. Chirdan LB, Uba AF: Hirschsprung's disease presenting in the neonatal period in Jos, Nigeria. Nigerian J Surg Res 2006, 8:62-64.

28. Bandre E, Kabore RAF, Quedraogo I, Sore O, Tapsola T, Bambara T, Wandaogo A: Hirschsprung's Disease; Management problem in a developing country. Afr J Pediatr Surg 2010, 7:166-168.

29. Archibong AE: Pattern of aganglionic megacolon in Calabar, Nigeria. S Afr Med J 2002, 92:642-644.

\begin{tabular}{|c|c|c|}
\hline $\begin{array}{l}\text { Age Group } \\
\text { (Years) }\end{array}$ & Male & Female \\
\hline $0-1$ & $10(50 \%)$ & $2(10 \%)$ \\
\hline $1-5$ & $6(30 \%)$ & $1(5 \%)$ \\
\hline $6-12$ & $1(5 \%)$ & Nil \\
\hline
\end{tabular}

\begin{tabular}{|c|c|c|}
\hline Age & $\begin{array}{c}\text { Hirschsprung's } \\
\text { disease } \\
\text { positive }\end{array}$ & $\begin{array}{c}\text { Hirschsprung's } \\
\text { disease Negative }\end{array}$ \\
\hline 1-6months & 10 & - \\
\hline 7months - 1 year & - & 1 \\
\hline 1-5 years & 6 & 2 \\
\hline 6-12 years & - & 1 \\
\hline \multicolumn{2}{|r|}{ Table 2: Age wise Stratification } \\
\hline
\end{tabular}

\begin{tabular}{|c|c|c|}
\hline Age & $\begin{array}{c}\text { Number cases } \\
\text { suspected as } \\
\text { HSD }\end{array}$ & $\begin{array}{c}\text { Number cases } \\
\text { diagnosed as } \\
\text { HSD }\end{array}$ \\
\hline$<1$ year & 11 & 10 \\
\hline$>1$ Year & 9 & 6 \\
\hline Table 3: Comparing the Age with the Suspected \\
Cases and Cases Diagnosed With HSD \\
\hline
\end{tabular}

\begin{tabular}{|c|c|c|c|}
\hline Sex & $\begin{array}{c}\text { Positive } \\
\text { for HSD }\end{array}$ & $\begin{array}{c}\text { Negative for } \\
\text { HSD }\end{array}$ & Total \\
\hline Male & 15 & 2 & 17 \\
\hline Female & 1 & 2 & 3 \\
\hline Total & $\mathbf{1 6}$ & $\mathbf{4}$ & $\mathbf{2 0}$ \\
\hline \multicolumn{3}{|r|}{ Table 4: Sex Ratio of the Patients } \\
Diagnosed with Hirschsprung's Disease \\
\hline
\end{tabular}

\begin{tabular}{|c|c|}
\hline Recto-sigmoid involvement & Total aganglionosis \\
\hline 15 & 1 \\
\hline \multicolumn{2}{|c|}{ Table 5: Intestinal Segment Involved in our HSD Patients } \\
\hline
\end{tabular}

